\section{Seroprevalence of brucellosis in different animal species of Kailali district, Nepal}

\section{Pandeya YR, ${ }^{*}$ Joshi DD, ${ }^{2}$ Dhakal $\mathbf{S}^{2}$ Ghimire L,1 Mahato BR,1 Chaulagain S,1 Satyal RC, ${ }^{1}$ Sah SK ${ }^{1}$}

${ }^{1}$ Institute of Agriculture and Animal Science (IAAS), Tribhuvan University, Rampur Campus, Chitwan, Nepal; ${ }^{2}$ National Zoonoses and Food Hygiene Research Center (NZFHRC), Kathmandu, Nepal

*Correspondence to: Dr. Yagya Raj Pandeya, Institute of Agriculture and Animal Science (IAAS), Tribhuvan University, Chitwan, Nepal, email: yagyarajpandeyavet@gmail.com, Tel No.: (+977)9845198374

\begin{abstract}
INTRODUCTION: Brucellosis is a contagious disease of livestock with significant economic impact. It is also a zoonotic disease, highly infectious for humans causing a disease called undulant fever or Malta fever. This study was carried out to determine the sero-status of Brucella spp. infection in cattle (cows), buffalo and goat in Kailali district of Far Western Region of Nepal.
\end{abstract}

MATERIALS AND METHODS: This cross-sectional study was conducted in Kailali district of Nepal during a period from September, 2012 to January, 2013. A total of 233 animal blood samples (50 Cattle, 67 Buffalo and 116 Goat) were collected and tested for Brucella antibody by plate agglutination test (PAT).

RESULTS: The seroprevalence of Brucellosis was $12 \%(28 / 233)$. Thirty two percentage $(16 / 50)$ of cattle, $13.4 \%(9 / 67)$ of buffaloes, and $2.6 \%$ $(3 / 113)$ goats were sero positive $(\mathrm{p}<0.05)$. Seroprevalence was higher in females $(14.6 \%$ vs. $10.6 \%)(\mathrm{P}>0.05)$ and was higher in younger cattles and older buffalo and goats ( $p>0.05)$.

CONCLUSIONS: This study showed that brucellosis exists as a potential threat in animals of Kailali district. This could be a potential source of infection to humans. Considering the high economic losses it can impart on livestock sector and the possible human health abnormalities, timely facilitation of awareness generation program and adoption of proper prevention and control strategies are recommended.

KEY WORDS: Food safety, Zoonoses, Plate Agglutination Test, Kailali district.

Article submitted 12 February. Reviewed 28 February. Author correction 5 March. Final version accepted 13 March 2013. 


\section{INTRODUCTION}

Brucellosis is an infectious disease characterized by abortion and infertility in several mammalian species, and is one of the most important zoonosis worldwide. ${ }^{1}$ Transmission occurs between animals mainly through contact with placenta, fetus, fetal fluids and vaginal discharges from an infected animal. Entry into the body occurs by ingestion and through the mucous membranes, broken skin and possibly through intact skin. ${ }^{3}$ Once infected the animal may continue to shed bacteria and remain a source of infection to others for long period. ${ }^{2}$ Species considered important agents of human diseases are B. melitensis, B. abortus and B. suis. ${ }^{4} B$. melitensis is the most invasive and most pathogenic for human and is major cause of Malta fever or undulant fever. $^{2}$ Brucellosis has been an occupational risk for farmers, veterinarians and employees in the meatpacking business. ${ }^{4}$ Nonoccupational sources of infection include consumption of fresh, unpasteurized raw fresh milk and milk products. ${ }^{5}$ In human, brucellosis can cause multisystemic disease with varying spectrum of symptoms. The clinical signs may in human include intermittent or irregular fever, headache, weakness, profuse sweating, chills, weight loss and general aching. Organ infections including liver and spleen may also occur. ${ }^{2}$

Brucellosis occurs worldwide but is much controlled in developed countries due to routine screening of domestic animals and animal vaccination program. Clinical disease is still common in Middle East, Asia, Africa, South and Central America, the Mediterranean Basin and the Caribbean. ${ }^{6}$ In one study in Pakistan, prevalence of brucellosis in cattle and buffalo was found to be 3\% using milk ring test and $8.5 \%$ through i-ELISA. ${ }^{7}$ In another study in Bangladesh, the overall seroprevalence was $2.9 \%$ in buffaloes, $2.7 \%$ in cattle and $3.2 \%$ in goat. ${ }^{8}$ In Punjab (India), overall 17.7\% prevalence of brucellosis was observed in cattle and buffaloes using milk ELISA procedure. The prevalence was non significantly higher in cattle than in buffaloes. ${ }^{9}$ Brucellosis in animals has already been reported from different districts of Nepal. Shrestha et al. found no seropositivity in buffaloes while $17.1 \%$ positivity in goat and $7.2 \%$ positivity in pigs. ${ }^{10}$ However, Mishra et al. found $23.2 \%$ prevalence of brucellosis in milking buffaloes through milk ring test. ${ }^{11}$

In Kailali district, most of the people are engaged in agriculture and livestock sector is the major contributor for livelihood. Considering the animal and human health disorders, occupational risks, and the economic burden it imparts, knowing the status of brucellosis infection in animals and establishing the epidemiology could be valuable for farmers, veterinarians, researchers, consumers, disease prevention and control program planners and any others concerned with better animal and human health. So, this study was carried out with the objective of determining sero-status of brucellosis infection in different animal species of Kailali district.

\section{MATERIALS AND METHODS}

This cross sectional study was carried out during a period of September 2012 to January 2013. Three areas of Kailali district, namely Dhangadhi municipality, Phulbari VDC and Ramshikarjhala VDC were selected for the study considering the time and financial constraint. Blood samples were collected from 116 goats, 67 buffaloes and 50 cattle. The serum was separated in Regional Veterinary Laboratory, Dhangadhi and the tests were done at National Zoonoses and Food Hygiene Research Centre's Laboratory in Kathmandu, Nepal. Cold chain was maintained during the transportation of samples. The test was carried out by using agglutination method and the kit developed by Human Gesellschaft fur Biochemica und Diagnostica, Germany. A drop $(50 \mu \mathrm{l})$ of Brucella test antigen was put on clean and sterile slide. To this a drop $(50 \mu \mathrm{l})$ of serum was added and slide was rocked for a minute. In positive case agglutination (clumping) was formed in the slide and in negative case there was no agglutination or clumping.

Statistical analysis was done by using MS-Excel 2007 and SPSS version 19. Descriptive statistics was used and data were considered significant at 5\% level of significance. Prevalence was calculated by percentage of the positive cases considering all the subjects under study. The association of the factors under study was tested by Fisher's exact test.

\section{RESULTS}

The seroprevalence of Brucellosis was $12 \%$ $(28 / 233)$. Thirty two percentage $(16 / 50)$ of cattle, $13.4 \%(9 / 67)$ of buffaloes, and $2.6 \%(3 / 113)$ goats were seropositive (Table 1). The seroprevalence of brucellosis among different animal species was statistically significant $(\mathrm{p}<0.05)$. Out of 151 male animals tested, $16(10.6 \%)$ were positive while 12 $(14.6 \%)$ females were positive out of 82 females tested (Table 1). However, no statistical differences were found between sex of animal and the sero- 
Table 1. Species and sex wise distribution of test results in animal

\begin{tabular}{llcccc}
\hline Factors & & Positive & Negative & Positive \% & p value \\
\hline \multirow{4}{*}{ Species } & Cattle & 16 & 34 & 32 & $<0.001$ \\
& Buffalo & 9 & 58 & 13.4 & \\
& Goat & 3 & 113 & 2.6 & 12 \\
Sex & Total & 28 & 233 & 10.6 & \\
& Male & 16 & 135 & 14.6 & $>0.05$ \\
\hline
\end{tabular}

Table 2. Age wise sero positivity in animals

\begin{tabular}{lccccc}
\hline Species & Age group (years) & Positive & Negative & Positive \% & p value \\
\hline Cattle & $\leq 7.8$ & 9 & 17 & 34.6 & $>0.05$ \\
& $>7.8$ & 7 & 17 & 29.2 & $>0.05$ \\
Buffalo & $\leq 7.1$ & 4 & 41 & 8.9 & $>0.05$ \\
& $>7.1$ & 5 & 17 & 22.7 & \\
Goat & $\leq 2$ & 1 & 83 & 6.2 & \\
& $>2$ & 2 & 30 & 6 & \\
\hline
\end{tabular}

vvere iunilu velvveen sex ui allindal allu ule seivpositivity $(p>0.05)$. The male to female ratio of seroprevalence was 1.33:1. Seroprevalence was higher in cattle, buffalo, and goat whose mean age was $\leq 7.8 y e a r s, \geq 7.1$ years and $\geq 2$ years, respectively. Although the seroprevalence was higher in younger cattle and higher in older buffalo and goats, this was not statistically significant ( $>>0.05)$ (Table 2).

\section{DISCUSSION}

A total of 233 animals were tested for Brucella infection by plate agglutination test. The overall prevalence in animals was $12 \%$ (32\% in cattle, $13.4 \%$ in buffaloes and $2.6 \%$ in goats). The prevalence in buffaloes was less than reported by Mishra et al. which was $23.22 \%$ however more than that reported by Shrestha et al. which was null. ${ }^{10,11}$ The prevalence in goat in this study was less than that reported by Shrestha et al. which was $17.1 \% .^{10}$ We found significant differences among species where cattle were found more infected than buffalo followed by goats. Higher seroprevalence in cattle than in buffalo was reported by the study carried out in Pakistan. ${ }^{7}$ Non-significantly higher prevalence was reported in cattle compared to buffalo in Punjab (India) as well. ${ }^{9}$

Among animal factors under study, age was not found to be associated significantly with whether or not the animal is likely to have Brucella infection. This was applicable for all species whether cattle, buffalo or goat. One study in Punjab (India) had shown significantly higher prevalence of brucellosis in cattle and buffaloes with older age. ${ }^{9}$ This study ivuilu illsigililcalliy iligiles seivpievaleille ill females compared to male animals. In Bangladesh as well prevalence was found to be relatively higher in females than males of cattle and goat whereas insignificantly higher prevalence was observed in male than female buffaloes. ${ }^{8}$ These findings suggest that all the animals irrespective of age and sex are vulnerable to infection of Brucella and pose potential threat to other animals as well as human beings.

In one study in Egypt, working with animals, breeding goats and eating ice cream bought from street vendors were found to be significantly associated with human brucellosis. ${ }^{12}$ In another study in Tanzania, human brucellosis was associated with assisted parturition during abortion in cattle, sheep or goat. ${ }^{13}$ In Korea, touching calves or placentas infected with Brucella species was found to be associated with human brucellosis. ${ }^{14}$ Thus, handling of aborted fetus and placental materials without any precaution and drinking raw milk can be the potential means for human infection with brucellosis in Nepal as well. Raw milk drinking habit exists in Nepalese society and the awareness about zoonotic diseases is very low. ${ }^{15}$ The seropositivity found in this study indicates the threat existing in these areas. In such circumstances, there is need of increasing public awareness for changing their behavior and practices together with implementation of regular screening and adoption of better prevention and control strategy, so as to protect animal and human health.

\section{CONCLUSION}

This study was carried out in a small area of 
Western Nepal taking a small population under investigation. Our study showed that brucellosis exists as a potential threat in animals of Kailali district irrespective of age and sex. The consumption of raw milk and meat products as well as improper handling of placenta and aborted fetus opens up chances for Brucella infection in human beings as well. Though the findings are of the particular area, it can somehow project the general condition of the country as a whole. This finding can be used as a baseline for future investigations and research on brucellosis in the country. Considering the high economic losses it can impart on livestock sector and the possible human health abnormalities, timely facilitation of awareness generation program and adoption of proper prevention and control strategies are needed. We recommend regular surveillance in animal and human, vaccination of animals and public awareness generation programs so as to reduce the health and economic burden of brucellosis in the country.

\section{ACKNOWLEDGEMENTS}

We would like to acknowledge D.D.J. Research Foundation for the financial support in this research. We are thankful to all the staffs of National Zoonoses and Food Hygiene Research Centre, staffs of Regional Veterinary Laboratory, Dhangadhi and all the farmers for their cooperation.

CONFLICT OF INTEREST: None to declare.

FINANCIAL INTEREST: None to declare.

\section{RERERENCES}

1. Cutler SJ, Whatmore AM, Commander NJ. Brucellosisnew aspects of an old disease. J Appl Microbiol 2005;98:1270-1281.

2. Corbel MJ. Brucellosis in human and animals. The World Health Organization in collaboration with the Food and Agriculture Organization of United Nations (FAO) and World Organization for Animal Health (OIE) 2006.

3. Xavier MN, Paixao TA, den Hartigh AB, Tsolis RM, Santos RL. Pathogenesis of Brucella spp. Open Vet Sci J 2010;4:109-118.

4. Young EJ. An overview of human brucellosis. Clin Infect Dis 1995;21:283-290.

5. Hartigan P. Human brucellosis: epidemiology and clinical manifestations. Irish Vet J 1997; 50:179-180.

6. Lopes LB, Nicolino R, Haddad JPA. Brucellosis-risk factors and prevalence: a review. Open Vet Sci J 2010;4:72-84.

7. Shafee M, Rabbani M, Sheikh AA, Ahmad MD, Razzaq A. Prevalence of bovine brucellosis in organized dairy farms, using milk ELISA, in Quetta city, Balochistan, Pakistan. Vet Med Inter 2011. doi:10.4061/2011/358950

8. Rahman MS, Faruk MO, Her M, Kim JY, Kang SI, Jung SC. Prevalence of brucellosis in Bangladesh. Vet Med 2011;56:379-385.

9. Aulakh HK, Patil PK, Sharma S, Kumar H, Mahajan V, Sandhu KS. A study on the epidemiology of bovine brucellosis in Punjab (India) using milk-ELISA. Acta Vet Brno 2008;77:393-399.

10. Shrestha B, Joshi DD, Aryal A, Shahi K. Serological evidence of brucellosis in different species of meat animals of Nepal. Zoonoses Food Hyg News 2008;14.

11. Mishra YP, Joshi DD, Gautam SP, Aryal A, Shahi K. Brucellosis in milking buffaloes of Bhaktapur milk shed areas. Zoonoses Food Hyg News;2009:15.

12. Meky FA, Hassan EA, Abd-Elhafez AM, Aboul-Fetouh AM, El-Ghazali SMS. Epidemiology and risk factors of brucellosis in Alexandria governorate. East Mediter Health J 2007;13:677-685.

13. John K, Fitzpatrick J, French N, et al. Quantifying risk factors for human brucellosis in rural Northern Tanzania. PLoS ONE 2010;5: e9968.doi:10.1371/journal.pone.0009 968.

14. Lim HS, Min YS, Lee HS. Investigation of a series of brucellosis cases in Gyeongsangbuk-do during 20032004. J Prev Med Public Health 2005; 38:482-488.

15. Pandey G, Dhakal S, Sadaula A, et al. Status of tuberculosis in bovine animals raised by tuberculosis infected patients in Western Chitwan, Nepal. Int J Infect Microbiol 2012;1;47-53.

\section{Citing this article}

Pandeya YR, Joshi DD, Dhakal S, et al. Seroprevalence of brucellosis in different animal species of Kailali district, Nepal. Int J Infect Microbial 2013;2(1);22-25. 